Article

\title{
Application of Flow Velocity and Direction Measurement System in Slope Stability Analysis
}

\author{
Qi Ge ${ }^{1}$, Jingjing Zhang ${ }^{2}$, Zhongxuan Chen ${ }^{3, *}$ and Jin $\mathrm{Li}^{4}$ \\ 1 College of Civil Engineering and Architecture, Zhejiang University, Hangzhou 310058, China; \\ geqi@zju.edu.cn \\ 2 Petrochina Hangzhou Research Institute of Geology, Hangzhou 310023, China; \\ Zhangij_hz@petrochina.com.cn \\ 3 Ocean College, Zhejiang University, Zhoushan 316021, China \\ 4 College of Biomedical Engineering \& Instrument Science, Zhejiang University, Hangzhou 310007, China; \\ li.j@zju.edu.cn \\ * Correspondence: czx722@zju.edu.cn; Tel.: +86-137-3552-3519
}

Citation: Ge, Q.; Zhang, J.; Chen, Z.; Li, J. Application of Flow Velocity and Direction Measurement System in Slope Stability Analysis. Water 2021, 13, 700. https://doi.org/10.3390/ w13050700

Academic Editor:

Francesco Gallerano

Received: 1 February 2021

Accepted: 1 March 2021

Published: 5 March 2021

Publisher's Note: MDPI stays neutral with regard to jurisdictional claims in published maps and institutional affiliations.

Copyright: (c) 2021 by the authors. Licensee MDPI, Basel, Switzerland. This article is an open access article distributed under the terms and conditions of the Creative Commons Attribution (CC BY) license (https:// creativecommons.org/licenses/by/ $4.0 /)$.

\begin{abstract}
Hydrodynamic pressure is often a crucial factor in the evaluation of slope stability analysis, especially for many rainfall-triggered landslides. Nevertheless, hydrodynamic pressure is rarely considered in the traditional limit equilibrium slice method of slope stability analysis since effective and reliable hydrodynamic pressure data are often lacking in practice. Moreover, efficient methods to involve these data in slope stability analysis are an urgent need. To overcome these concerns, the flow velocity and direction system (FVDS) is employed to measure the groundwater flow velocity, which can be used to generate hydrodynamic pressure samples at different monitoring points. Based on these samples, the hydrodynamic pressure of each soil strip is estimated using artificial neural networks (ANNs). Afterward, an improved Bishop method that considers hydrodynamic pressure is proposed. The effectiveness and significance of the proposed method are illustrated with a case study, the Fanshantou landslide in Zhejiang Province, China. The safety factor before and after taking drainage countermeasures is also calculated and compared. The results indicate that hydrodynamic pressure plays an important role in the stability analysis of the Fanshantou landslide. Compared with the classical Bishop method, the improved method is shown to agree better with the actual deformation characteristics of the landslide.
\end{abstract}

Keywords: landslide; slope stability analysis; hydrodynamic pressure; groundwater monitoring; artificial neural networks

\section{Introduction}

Groundwater is an important factor and is usually considered a static quantity [1-3], while the dynamic component [4] is rarely considered in slope stability analysis. Specifically, current research on investigating groundwater-related impact factors is mostly limited in scope to the hydrostatic aspects, such as pore water pressure, water content, and groundwater level $[5,6]$. Though significant, these factors cannot represent all the impact of groundwater on landslides. Meanwhile, even though the movement of groundwater in certain areas is dynamic, the hydrodynamic factors of groundwater, such as groundwater flow velocity and flow direction, are rarely exploited in related studies [7]. With the improvement of monitoring equipment and the application of digitized facilities, the hydrodynamic aspect of groundwater provides a promising research topic for exploring the influential factors that can lead to landslides.

The velocity and direction of groundwater flow are the two main influential factors [8] in terms of the hydrodynamic characteristics of groundwater. As a powerful and advanced technique in the geotechnical survey of landslides, the flow velocity and direction system (FVDS) has been applied to measure the velocity and direction of groundwater in slope 
areas [9,10]. In 1987, Itanium and others first used the FVDS to explore the state of groundwater movement and determined the accuracy of the results through experiments [8]. In 1997 and 1999, Kreal and others used the FVDS to measure the flow direction of groundwater again in the United States and compared the results with the results from the traditional measurement methods [11]. Olea et al. [12] evaluated the velocity and direction of groundwater by applying the FVDS in the basin of Mexico. In 2015, Pan et al. [13] used the FVDS to analyze the stability of the Heifangtai landslide in Gansu, China, but only performed a qualitative analysis. In the previous studies, the FVDS was applied to the transport of pollutants in groundwater on the one hand and to explore the direction of groundwater flow on the other hand. However, the flow rate information was often overlooked. At the same time, in slope stability analysis, little attention is paid to the influence of groundwater flow on the safety factor. Therefore, the FVDS still has broad application prospects in landslide stability analysis. Applying the FVDS to landslide stability analysis is innovative research. However, it is impossible to use the FVDS to measure the groundwater flow velocity of each soil strip for slope stability calculations when the powerful FVDS is combined with the traditional limit equilibrium slice method. Based on the assumption that the velocities of groundwater flow are always continuous, the artificial neural network (ANN) [14] is employed to estimate the velocity of continuously changing flow by using the FVDS-based flow velocity data.

Therefore, in this study, the Fanshantou landslide in Zhejiang Province, China, is taken as a case to illustrate the application of the FVDS in the geotechnical survey. We have proposed an improved calculation method of the safety factors according to the measurement results of the flow velocity, compared with those of the traditional calculation, by incorporating the hydrodynamic characteristic of the groundwater. The results in the case study show that the safety factor of the landslide decreased significantly and agreed better with the actual situation of the case on considering the effect of hydrodynamic pressure, which indicates that hydrodynamic pressure plays an important role in the stability analysis of the Fanshantou landslide. Although this article only discusses the impact of hydrodynamic pressure on the safety factor in one case, it shows that ignoring hydrodynamic pressure may lead to misjudgment of landslide stability. It shows that detailed investigations and research on groundwater are very important for the evaluation of slope stability.

\section{Overview of the Case Landslide}

\subsection{Regional Geological Condition}

The case landslide is located in Songyang County, Lishui City, Zhejiang Province, China (Fanshantou landslide in Figure 1). The area has a subtropical monsoon climate, and the precipitation is mainly concentrated in the seasons of rainy and typhoon rainy, from March to September each year. From March to June is the rainy season, and the average cumulative rainfall is $822.05 \mathrm{~mm}$, which accounts for $52.32 \%$ of the total annual rainfall. During this period, cold and warm air currents meet, the rainfall is abundant, the rainfall time is long, and geological disasters are prone to be induced. It is the typhoon rainy season from July to September, and the average cumulative rainfall is $367.05 \mathrm{~mm}$, which makes $24.23 \%$ of the annual rainfall. It is characterized by extensive short-duration, high-intensity rainfall concentrated in small areas, leading to a high possibility of geological disasters.

The total volume of the potential landslide area was about $285 \times 10^{4} \mathrm{~m}^{3}$, and the volume of the soil with creep deformation at the front edge was about $15 \times 10^{4} \mathrm{~m}^{3}$. A landslide is a translational landslide in which the surface soil slides along the bedrock surface. The overall landslide area presents the characteristics of being high in the south while being low in the west. The azimuth of the sliding direction is about $220^{\circ}$. The leading-edge elevation is about $440 \mathrm{~m}$. The trailing edge elevation is about $560 \mathrm{~m}$, and the maximum elevation difference is $120 \mathrm{~m}$. The plan view of the landslide area is shown in Figure 2. 


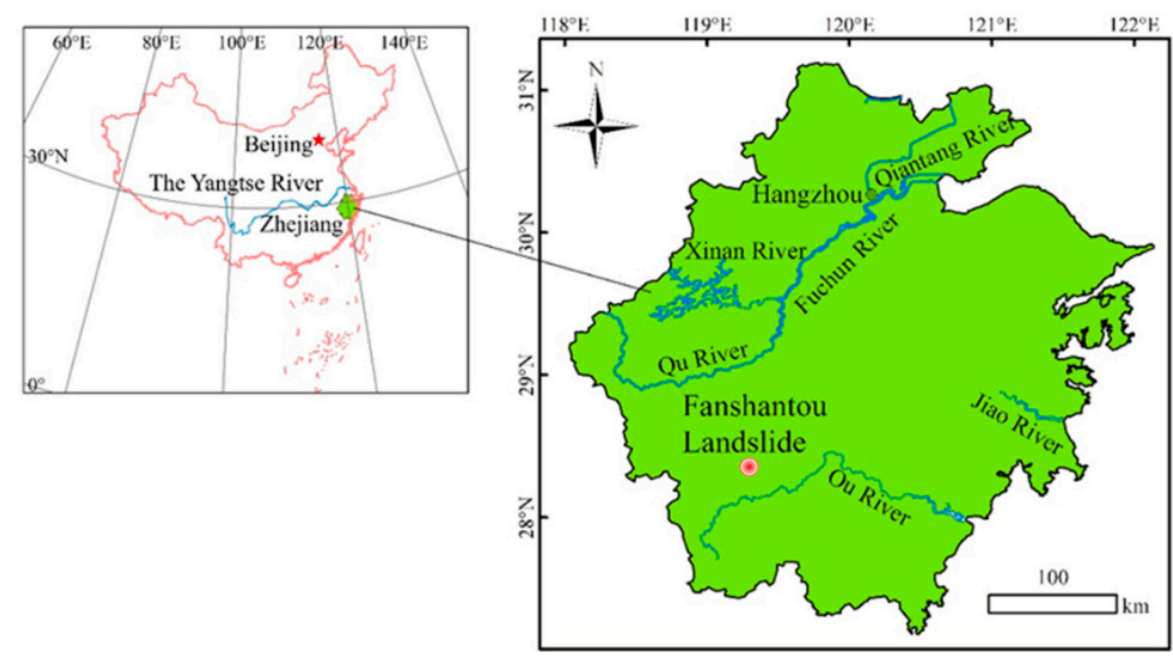

Figure 1. Position of the Fanshantou landslide.

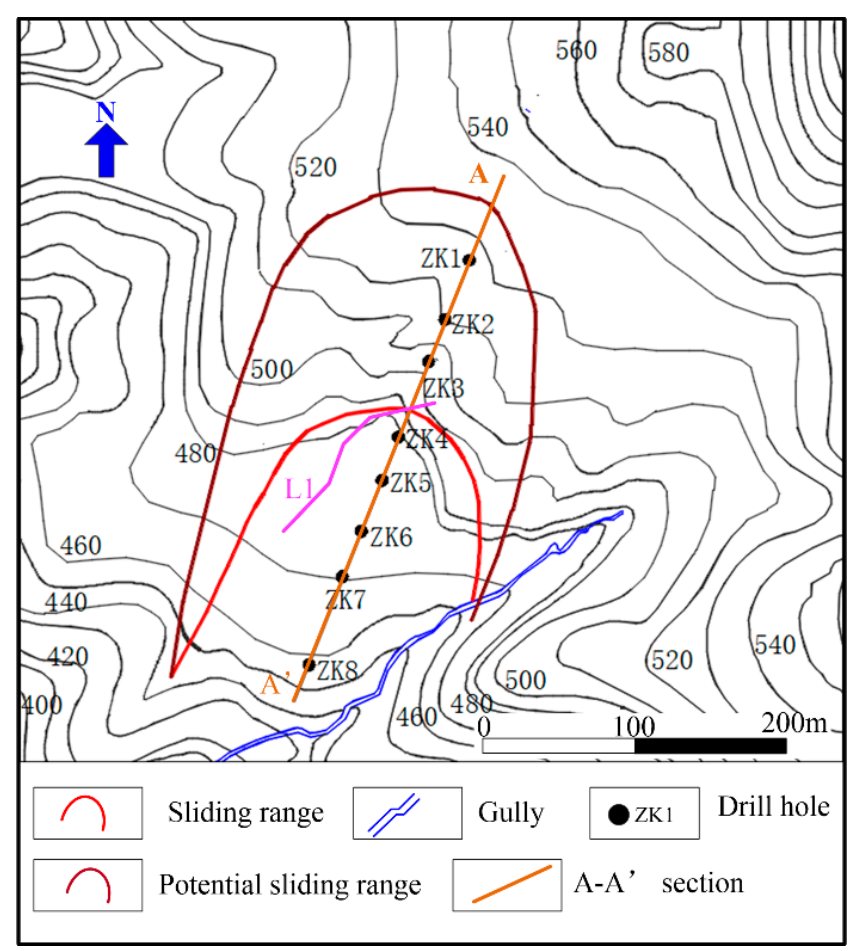

Figure 2. Plan view of the Fanshantou landslide.

The section view in the main direction (section A-A') of the landslide is shown in Figure 3. The stratum (including the soil layer and the rock layer) structure of the landslide body can be divided into obvious upper, middle, and lower layers. The upper layer consists of gravel with clay with a thickness of 1.4-9.4 m, of poor permeability $\left(\mathrm{k}=7.16 \times 10^{-8} \mathrm{~m} / \mathrm{s}\right)$. The color of this layer is grayish yellow, and the content of breccia is about $5 \%$. The grain size of the gravel is $0.2-2 \mathrm{~cm}$, and the rest is cohesive soil. The number of hammers in the cone dynamic penetration test is $5-9$ per $10 \mathrm{~cm}$, with a relatively mixed and uniform composition. The middle layer is silty clay with breccia. The breccia may be related to the nearby faults, but detailed geological surveys do not find any fault activity that affects the stability of the slope. The trailing edge is very thick, while the leading edge is not. The permeability is good $\left(\mathrm{k}=4.85 \times 10^{-6} \mathrm{~m} / \mathrm{s}\right)$, and the particle size is between $2 \mathrm{~cm}$ and $15 \mathrm{~cm}$. The color is gray to gray yellow, the particle size distribution is poor, and the change is large. The content of gravel is $50-75 \%$. Some boreholes contain boulders, the diameter of 
which is $20-40 \mathrm{~cm}$. The parent rock of the gravel is tuff. It is easy for it to collapse and fall off. The lower layer is the underlying bedrock, of which the surface is strongly weathered or fully weathered, and the main components are tuff and muddy siltstone. The color is gray to gray black, and the structure is silty, layered, tuffaceous, or block and relatively complete. The landslide area has been affected by faults in history, and more fractures were developed, but there has been no active fault since the Quaternary.

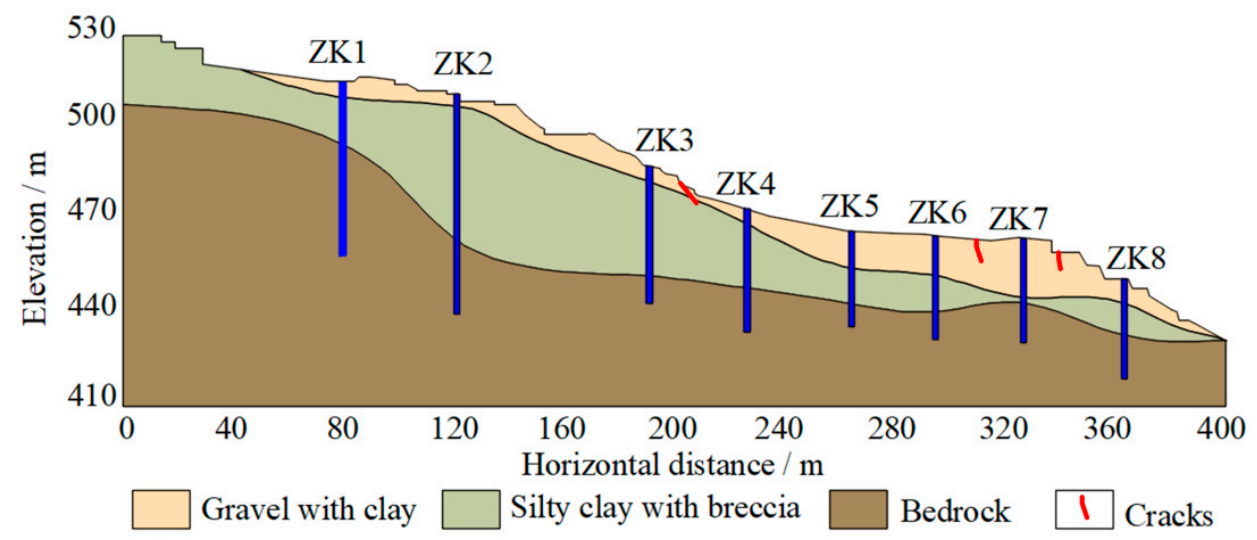

Figure 3. Section view of A-A'.

The landslide area belongs to a fault block in the mid-mountain landform area that is dominated by pyroclastic rocks and metamorphic rocks in southwestern Zhejiang. The direction of the slope is $220^{\circ}$, and the elevation of the slope toe is $350 \mathrm{~m}$. The maximum elevation of the catchment area where the landslide is located is $578.12 \mathrm{~m}$, and the height difference is $228.12 \mathrm{~m}$. The slope is steep in the upper area, moderately steep in the middle part, and steep in the lower part (Figure 4); and the gradient of the upper slope is $25-35^{\circ}$, the middle part is $5-15^{\circ}$ (landslide section), and the lower part is $25-35^{\circ}$. Residential areas and cultivated land are located in a relatively flat section in the middle of the slope. The Tongcun Highway winds up along the mountain from the steep lower part, cutting the mountain more and forming a slope with a general height of $3-5 \mathrm{~m}$. There is a gully at the front edge of the landslide. However, since no damage feature is found in the gully range and it is located far from the landslide, the influence of the gully is not considered here.

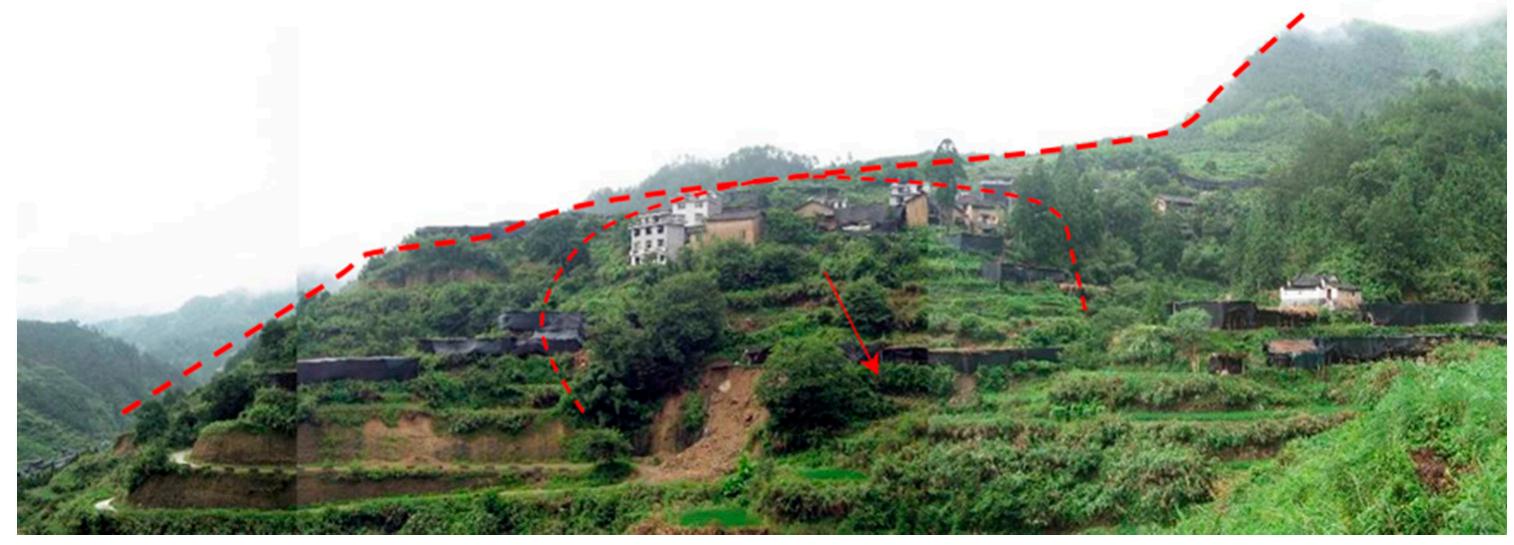

Figure 4. The Fanshantou landslide.

\subsection{Failure Characteristics of the Case Landslide}

The Fanshantou landslide is a translational landslide, and the sliding surface is the top surface of the bedrock. The discovery of deformation and failure features was made from the reports of the residents and on-site inspections by investigators. The failure 
characteristics of the landslide were first discovered in July 2010, and many cracks appeared on the front edge of the landslide area (Figure 5a,b). A large crack L1 appeared on the trailing edge on the north side of the landslide. The widest point of L1 reached $15 \mathrm{~cm}$, and the crack gradually expanded. By August 2010, the maximum width of L1 reached $25 \mathrm{~cm}$. Although some emergency measures were taken, such as filling the cracks with cement, the cracks were found to expand again in June 2012 (Figure 5c). From then, the widths and depths of the cracks increased after several rains. In September 2013, an engineering geological survey of the entire landslide body showed that there were many new cracks in the area (Figure 5d). In June 2015, the landslide area was re-examined and it was found that some houses on the landslide body were significantly inclined, so it was decided to relocate the village (Figure 5e).

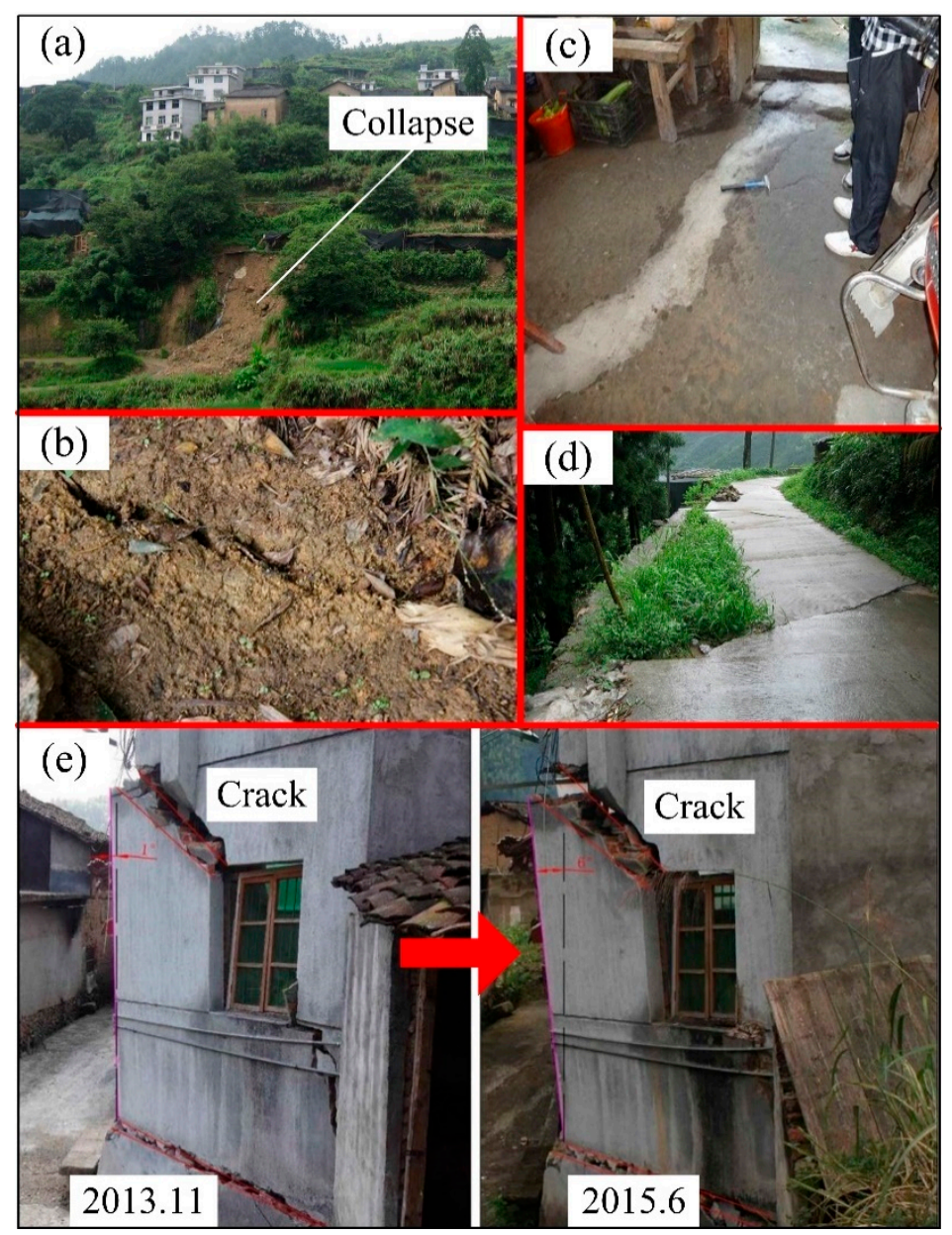

Figure 5. The deformation and failure characteristics of the Fanshantou landslide. (a): Collapse in the front of the landslide; (b): Cracks in the front of the landslide; (c): Cracks in the north side of the landslide; (d): New cracks in the north side of the landslide; (e): Cracks of buildings in the middle of the landslide.

\section{Materials and Methods}

\subsection{Measuring Principle of the FVDS}

The flow velocity and direction system (FVDS) is a device that combines a highresolution magnetic flux valve compass and a high-magnification colloidal particle tracking camera. The composition and probe structure of the FVDS are shown in Figure 6. Both the compass and the camera are located in the probe. The measurement principle of the FVDS is to obtain a series of images of colloidal particles in groundwater by setting a shorter camera shooting interval. The processing software combines the two adjacent images into one image and connects the positions of the same particle in the two images. The 
compass in the probe can get the movement direction of the connection. The movement speed of the colloidal particles can be obtained from the length of the connection line and the interval of the shooting time. The movement direction and speed of these colloidal particles represent the flow direction and velocity of the groundwater. It should be noted that because a probe that is just placed in the borehole will interfere with the flow state of the groundwater, it is necessary to leave the probe in the borehole for a while to get a more realistic measurement result.

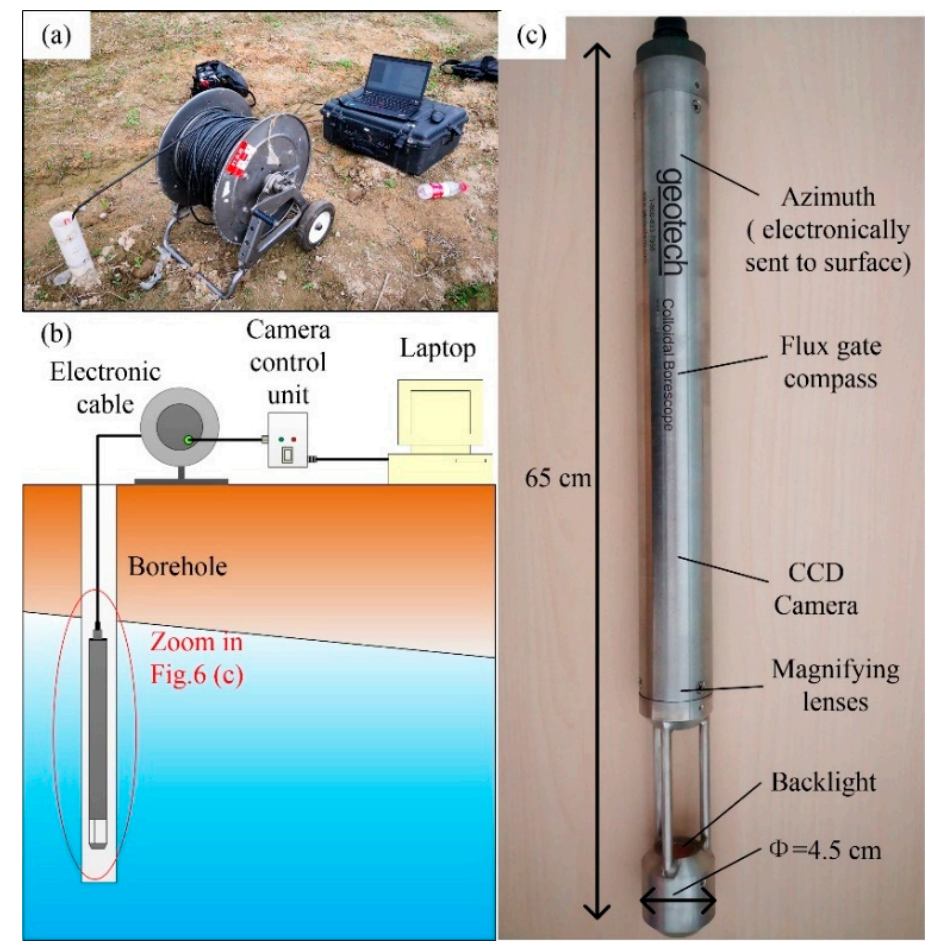

Figure 6. Composition and probe structure of the flow velocity and direction system (FVDS). (a) Photo of the FVDS in use on-site. (b) Composition of the FVDS. (c) Probe structure of the FVDS.

In the system, the direction and speed of the movement of the groundwater are represented by the direction and speed of the movement of the tiny particles in the groundwater. During field measurement, the FVDS uses the boreholes in the survey and ensures that the instrument probe is below the groundwater surface. Because the tiny particles that naturally exist in the water flow with the water, if the direction and speed of these particles are obtained, then the direction and speed of the groundwater could be obtained. The smaller the particles, the better the true flow rate of the groundwater could be rep-resented. With the help of a camera on top of the probe that can give a magnification of $\times 130$, the instrument can capture and take pictures of tiny particles in the groundwater. The camera of the instrument also has the function of taking pictures continuously and saving the shooting time of each picture.

At the same time, the compass in the probe automatically marks the position of each photo. The cable is for transferring the captured photos to the computer for subsequent processing. The computer could compare one or several consecutive photos and find the same particles in the two photos. According to the time interval between the two photos, first the distance the particle has moved and the change of the movement position are obtained and then the particle's speed and movement direction are obtained. Finally, the flow direction and velocity of the groundwater are obtained.

In previous studies, the FVDS was applied to the transport of pollutants in groundwater on the one hand and to explore the direction of the groundwater flow on the other hand. However, the flow rate information is often overlooked. At the same time, in slope 
stability analysis, little attention is paid to the influence of groundwater flow on the safety factor. Therefore, applying the FVDS to landslide stability analysis is innovative research.

\subsection{Improved Bishop Method Considering Hydrodynamic Pressure}

Among the many methods for calculating the slope safety factor, the Bishop method has been widely used for its good accuracy $[15,16]$. However, the Bishop method only considers the hydrostatic pressure effect of the groundwater. Although some researchers tried to introduce hydrodynamic pressure or seepage force into the Bishop method, the calculation process of the improved method was still not convincing enough $[17,18]$. For landslide areas, the situation of the groundwater is very complicated and the groundwater flow along the sliding direction will have an effect on the slope safety factor. Therefore, based on the Bishop method, the hydrodynamic pressure was introduced to calculate the safety factor of the slope.

In the improved method, the stress analysis of the $i$-th soil strip is shown in Figure 7. In the calculation, it is assumed that the component forces of the vertical inter-strip force are equal in value and opposite in direction. $J_{i}$ is the hydrodynamic pressure on the strip, and the direction of the pressure is down along the bottom of the strip. Then the vertical force balance equation of the soil strip is as follows:

$$
W_{i}+J_{i} \sin \alpha_{i}=T_{i} \sin \alpha_{i}+\left(N_{i}+u_{i} l_{i}\right) \cos \alpha_{i}
$$

where $W_{i}$ is the weight of the $i$-th soil trip (see Figure 7), and its unit is $\mathrm{kN} / \mathrm{m} ; J_{i}$ is the seepage force of the $i$-th soil trip, and its unit is $\mathrm{kN} / \mathrm{m} ; \alpha_{i}$ is the slope of the bottom of the $i$-th soil trip; $T_{i}$ and $N_{i}$ are the tangential force and the normal force of the $i$-th soil trip on the bottom surface, respectively, and the unit is $\mathrm{kN} / \mathrm{m}$; and $u_{i} l_{i}$ is the pore water pressure of the $i$-th soil trip, and the units are $\mathrm{kPa}$ for $u_{i}$ and $\mathrm{m}$ for $l_{i}$.

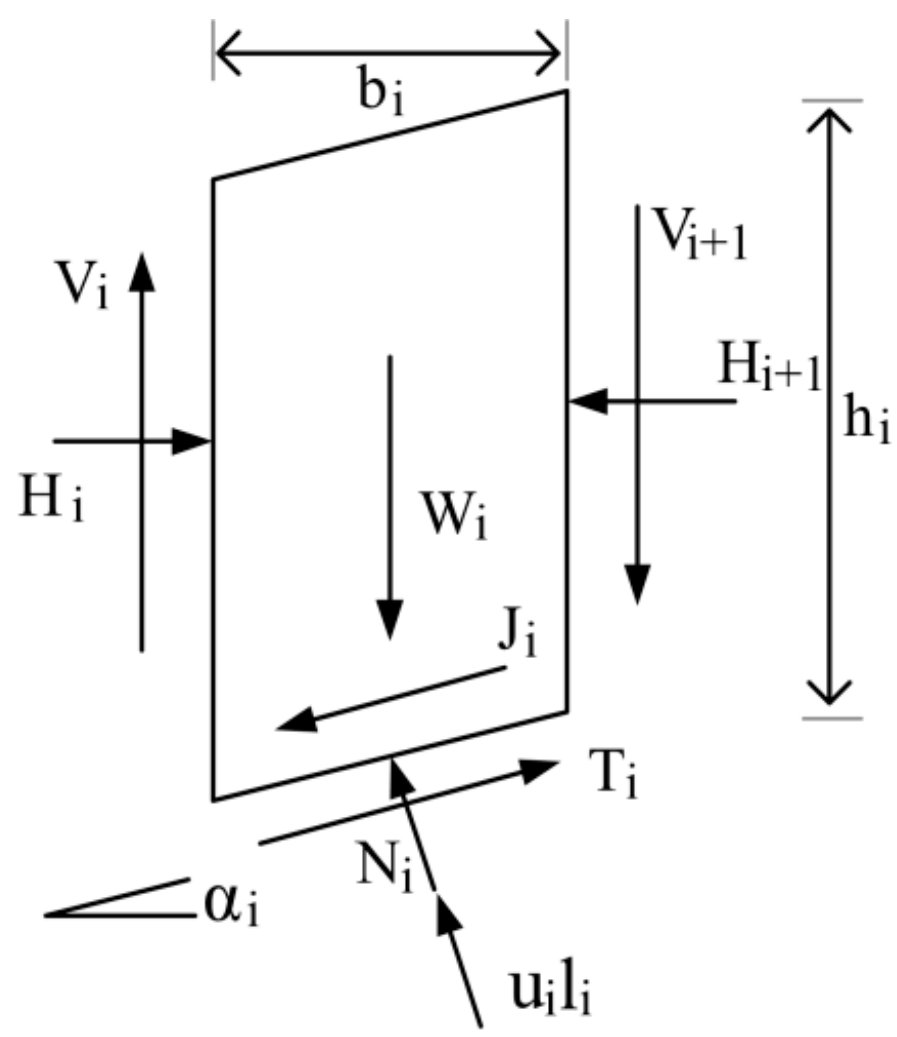

Figure 7. Diagram of the force analysis of the $i$-th soil trip. 
Because in the calculation, there is a fixed relationship between $T_{i}$ and $N_{i}$ :

$$
T_{i}=\frac{1}{F_{S}}\left(c_{i} l_{i}+N_{i} \tan \varphi_{i}\right)
$$

where $c_{i}(\mathrm{kPa})$ is the cohesion of the $i$-th soil trip and $\varphi_{i}$ is the internal friction of the $i$-th soil trip.

Simultaneously, from Equations (1) and (2), the following derivation can be obtained:

$$
N_{i}=\frac{1}{m_{i}}\left(W_{i}+J_{i} \sin \alpha_{i}-\frac{c_{i} l_{i} \sin \alpha_{i}}{F_{S}}-u_{i} l_{i} \cos \alpha_{i}\right)
$$

where

$$
m_{i}=\cos \alpha_{i}+\frac{\tan \varphi_{i} \sin \alpha_{i}}{F_{s}}
$$

When the forces of the soil strip are summed to the center of the sliding arc, the internal force between the soil strips does not appear in the equilibrium equation. In addition, in order to simplify the calculation, the center of the bottom of the soil strip is regarded as the point of the action of $J_{i}$.

$$
\sum T_{i} r=\sum W_{i} r \sin \alpha_{i}+\sum J_{i} r
$$

where $F_{S}$ is the safety factor and $\mathrm{r}$ is the distance to the point of action and its unit is $\mathrm{m}$.

Substituting Equations (1)-(4) into Equation (5) and substituting $b_{i}=l_{i} \cos \alpha_{i}$ at the same time, we obtain the following equation for the calculation of the safety factor after the hydrodynamic water pressure is considered:

$$
F_{S}=\frac{1}{\sum\left(W_{i} \sin \alpha_{i}+J_{i}\right)} \sum \frac{c_{i} b_{i}+\left(W_{i}+J_{i} \sin \alpha_{i}-u_{i} b_{i}\right) \tan \varphi}{m_{i}}
$$

Since the real geological profile is very complicated, especially the interface of each layer being difficult to deal with in the calculation, the geological profiles of the landslides need to be simplified. Based on the real stratum structure, the curve boundary of the stratum is transformed into a straight line and the thickness and position of the stratum after simplification are basically consistent with the real situation. The simplified geological profile of the Fanshantou landslide is shown as Figure 6. In the process of simplification of the section, the characteristics of the original local layer are retained. For the Fanshantou landslide, the most important geological features are the following (see Figure 8 for illustration): (1) There is a silty clay layer on the surface. (2) The gravel soil layer is very thick at the trailing edge and thin at the leading edge. (3) The bedrock has a large inclination at the trailing edge, but it is fairly flat at the leading edge. The physical and mechanical parameters of each soil layer are shown in Table 1.

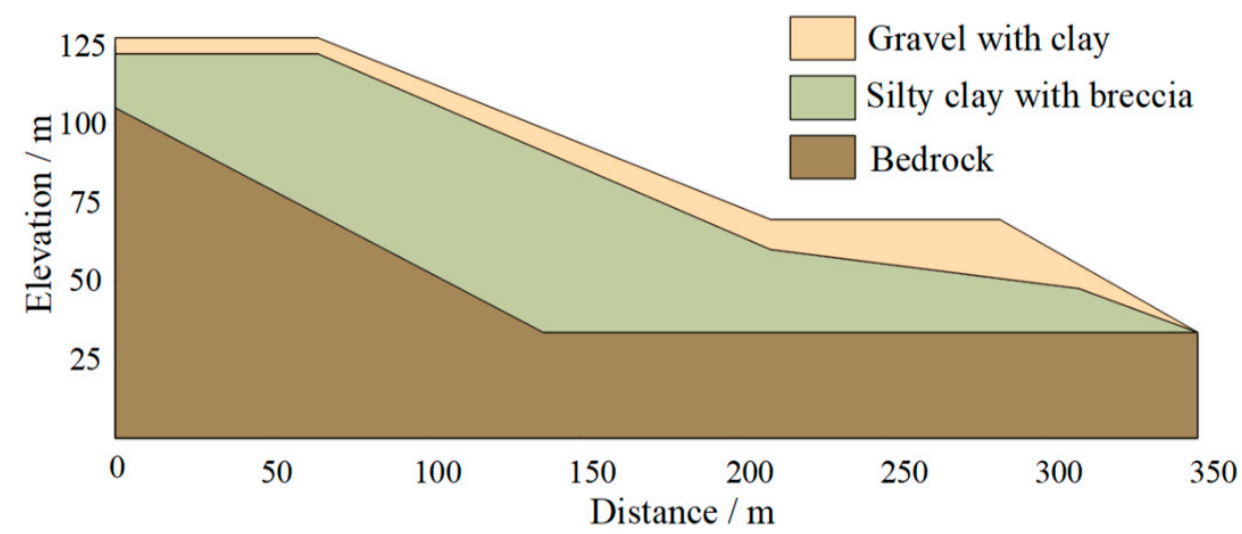

Figure 8. Simplified section for calculation of the safety factor. 
Table 1. Physical and mechanical parameters of soil layers.

\begin{tabular}{cccc}
\hline Soil & $\gamma / \mathbf{k N} \cdot \mathbf{m}^{-\mathbf{3}}$ & $\mathbf{c} / \mathbf{k P a}$ & $\boldsymbol{\varphi}$ \\
\hline Gravel with clay & 18.19 & 12.5 & $12.5^{\circ}$ \\
Silty clay with breccia & 18.66 & 3 & $24.5^{\circ}$ \\
Strongly weathered bedrock & 19.30 & 22 & $16.0^{\circ}$ \\
\hline
\end{tabular}

\subsection{Estimation of Hydrodynamic Pressure Based on ANNs}

According to Section 3.2, the equation to calculate the safety factor of a slope has been obtained by considering the hydrodynamic pressure. However, in Equation (6), the hydrodynamic pressure $J_{i}$ of each soil strip needs to be considered. According to Darcy's law, the relationship between groundwater flow velocity and hydrodynamic pressure is:

$$
J_{i}=\frac{v}{k} \gamma_{w}
$$

In the formula, $J_{\mathrm{i}}$ is the hydrodynamic pressure of the groundwater in the $i$-th soil strip, $v$ is the flow velocity of the groundwater, $k$ is the permeability coefficient of the soil at the measurement location, and $\gamma_{\mathrm{w}}$ is the gravity of the water.

However, for landslides, it is impossible to measure the groundwater flow velocity for each soil strip. When measuring groundwater flow velocity, the FVDS has certain requirements in terms of the diameter and wall conditions of the borehole and the number of boreholes in the area is limited. In addition, the groundwater velocity is affected by many factors, such as the groundwater level, the inclination of the bedrock, and the distribution of geological structures. Therefore, it is difficult to establish an equation to calculate the regional groundwater flow velocity from the monitoring data of boreholes. However, in a landslide, the groundwater velocity curve on a profile line should be continuous and smooth. Therefore, the velocity of the groundwater cannot be calculated accurately but it can be estimated by using the borehole data.

It is a typical curve fitting problem to estimate the velocity of continuously changing flow by using the known flow velocity data. The objective of curve fitting is to construct a curve or derive mathematical functions that can exhibit close proximity to the real observations. Traditional curve fitting methods, such as linear and cubic polynomials, can provide a simple solution for the nonlinear curve fitting problem. However, substantial performance improvement can be obtained using the artificial neural network (ANN). Though the calculation of the ANN is generally more computationally intensive than that of the linear algorithm, the predictive ability of the model is usually optimal. Therefore, the ANN is employed in this study. Some advanced methods, such as artificial-delaybased methods $[19,20]$ can also be alternate ways to estimate an unknown function via input/output data.

When fitting a curve by using the generalized regression neural network (GRNN), with only limited points, the curve can be well fitted [21]. The GRNN is a radial basis function neural network that has a simple training procedure and unique adjustment parameters. The GRNN consists of four layers: the input layer, the pattern layer, the summation layer, the and output layer [22]. The input vector is $X=\left(x_{1}, x_{2}, \ldots, x_{m}\right)^{T}$ and the corresponding output is $Y=\left(y_{1}, y_{2}, \ldots, y_{k}\right)^{T}$. The dimension of the input vector is $m$, the dimension of the output vector is $k$, and the number of samples is $n$. The GRNN could adjust the network structure according to the training samples automatically. In addition, the number of nodes need not be determined by the users. The transfer function of the $i$-th neuron in the model layer is:

$$
P_{i}=\exp \left[-\frac{\left(X-X_{i}\right)^{T}\left(X-X_{i}\right)}{2 \sigma^{2}}\right]
$$


where $X$ is the input variable of the network, $X_{i}$ is the corresponding training sample of the $i$-th neuron, and $\sigma$ is the smoothing parameter.

The summation layer contains two types of neurons. One type performs the arithmetic summation of all the output of the model layer, and the connection weight between each neuron and this neuron in the model layer is 1 . The other type performs a weighted summation of all the output of the pattern layer. The number of neurons in the output layer is equal to the dimension of the output vector in the model sample [23]. Therefore, the structure and weight of the GRNN are fully determined after the selection of the model sample. As a result, the GRNN is more convenient than the other neural networks. As the GRNN is an updated version of the basic ANN model, we refer to it as ANN instead in the following sections for consistency.

\section{Result}

When the FVDS was used to measure the groundwater flow velocity in the area, there were high requirements for the conditions of the borehole diameter and the hole wall. When there are at least two sets of orthogonal through-holes in the perforated pipe of the borehole wall, the accuracy of the measurement results can be guaranteed [13]. At the same time, the diameter of the borehole should be more than twice that of the probe diameter. In the landslide area, only a few boreholes meet the measurement conditions. The measurement results of the groundwater flow velocity of five boreholes (ZK2, ZK3, ZK6, ZK7, and ZK8) are shown as Figure 9. As for the direction data of the flow, it basically points to the main sliding direction of the landslide or the adjacent gully. Since this research was focused on regional groundwater flow velocity data, the flow direction data is not discussed in more detail.

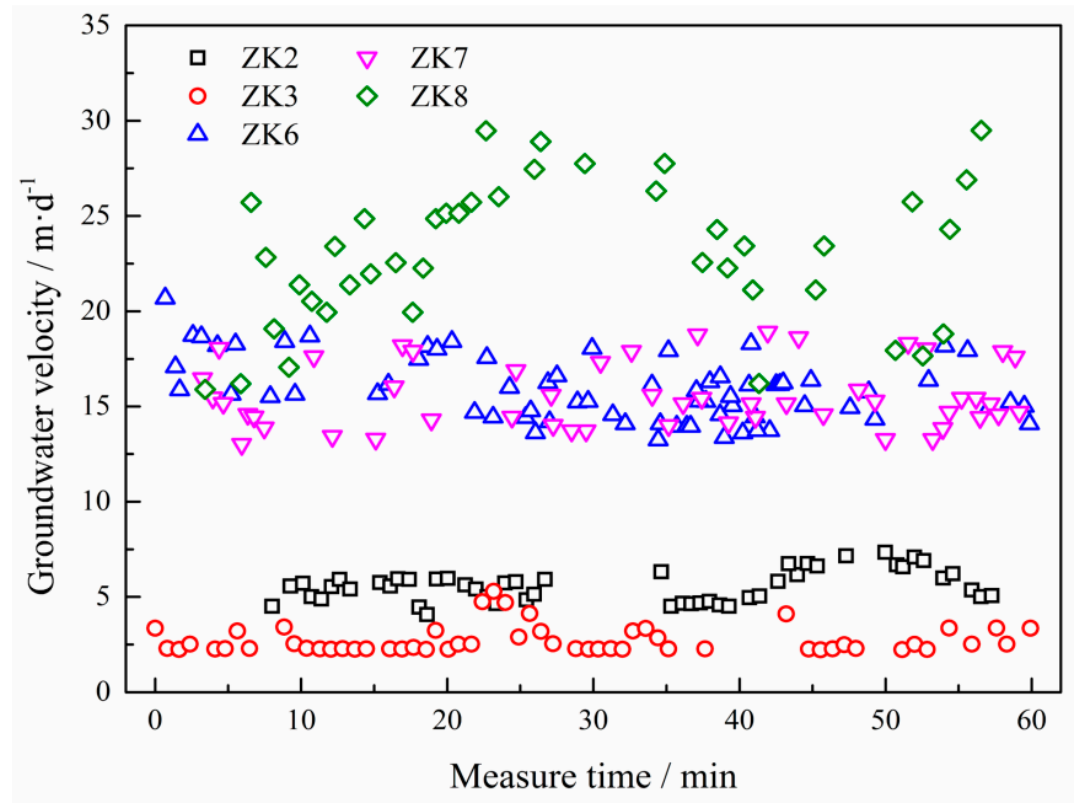

Figure 9. Groundwater flow velocity of five boreholes.

Figure 9 shows that the groundwater flow velocity in the area varies greatly; the highest flow velocity reaches $26 \mathrm{~m} / \mathrm{d}$ (ZK8), while the lowest in the measurement is only $3 \mathrm{~m} / \mathrm{d}$ (ZK3). Large changes in flow velocity indicate that the groundwater movement in the landslide is active. However, from the monitoring data of the groundwater level, it is difficult to identify the change in the groundwater velocity intuitively. In addition, the distribution of the groundwater flow velocity in Fanshantou landslide shows that the flow is fast at the trailing edge and the leading edge but it is slow at the middle of the landslide. Such velocity characteristics are closely related to the hydrogeological conditions of the region. 
By taking the average of the measurement results of each borehole in Figure 9, the groundwater velocity of the borehole could be obtained. Because all the measured boreholes are on the $\mathrm{A}-\mathrm{A}^{\prime}$ profile, the groundwater velocity information on this profile can be restored. Based on the groundwater velocity of five boreholes, the fitted curve can be obtained by using the ANN method. In the ANN model, the dimension of the input data is 2 (velocity and distance); $R$-squared is taken as the evaluation metric; the 5 -fold cross-validation method was used (i.e., 4 samples for training and 1 for testing in each turn) to validate the model. The result of curve fitting is shown as Figure 10. In Figure 10, the horizontal axis is the distance from the trailing edge to the leading edge of the landslide and the vertical axis is the flow velocity of the groundwater in the landslide. The groundwater velocity of landslides is closely related to hydrogeological conditions. Hydrogeological conditions not only determine the inclination of the groundwater in the rock and soil layer, the recharge and discharge conditions of the groundwater, and the hydraulic gradient, but also determine the type of groundwater. Submersible water and confined water usually have different flow speeds.

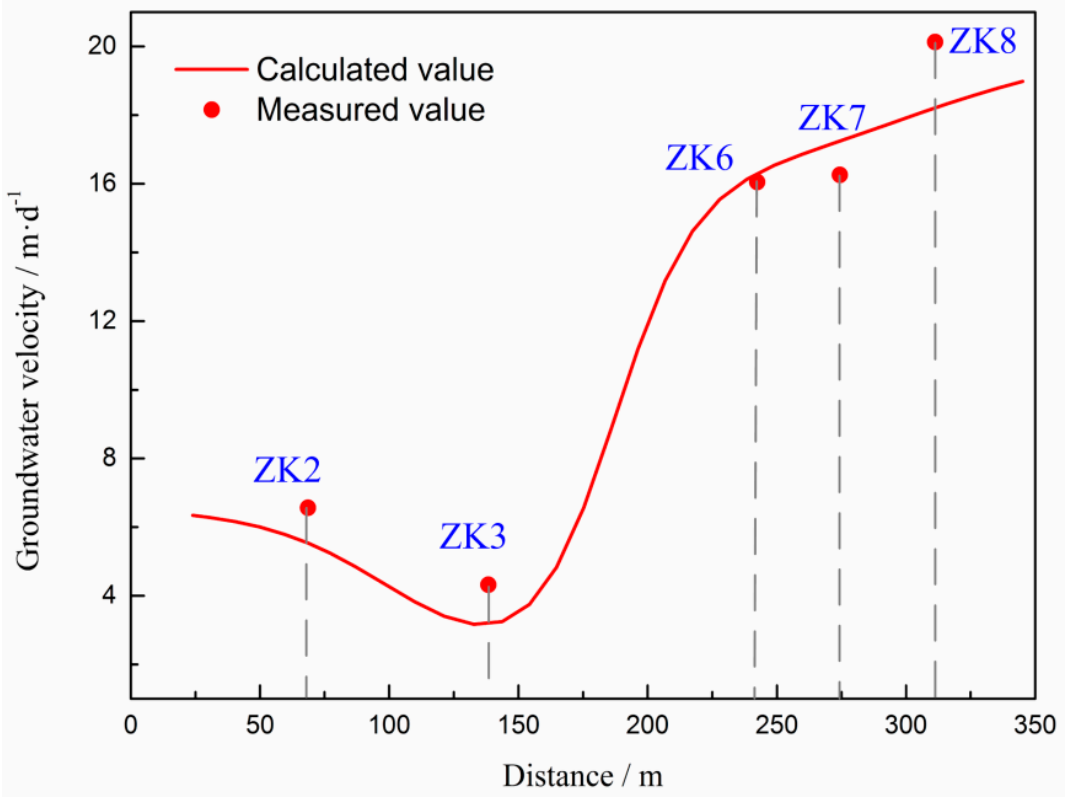

Figure 10. Groundwater flow velocity and fitting curve.

The flow velocity distribution law in Figure 10 is consistent with the stratum structure characteristics of the Fanshantou landslide. For the Fanshantou landslide, the permeability of the silty clay and bedrock on the surface of the slope is poor, so groundwater mainly exists in the gravel soil layer. The inclination and thickness of the gravel soil layer have become the main influencing factors of the groundwater velocity. At the trailing edge of the landslide, because the thickness of the gravel soil layer with good permeability is large, the groundwater flow rate mainly depends on the inclination of the bedrock. In the middle of the landslide, the bedrock is flat (the inclination of the rock formation is less than $20^{\circ}$ ) and the hydraulic gradient decreases, so the groundwater flow velocity decreases. At the leading edge of the landslide, the thickness of the gravel soil layer decreases rapidly and the area of the groundwater overflow cross-section decreases rapidly, resulting in an increase in the groundwater flow velocity. The monitoring data of groundwater velocity also shows that the slope of the bedrock will lead to an increase in the speed of the groundwater, but compared with the reduction of the flow section, the latter will accelerate the velocity of the groundwater more significantly. This is because apart from the increase in the slope, the groundwater velocity will also be affected by other factors, such as the permeability of the rock and soil. In confined water, the reduction of the flow cross-section is more intuitive and the effect on the velocity is more significant. Therefore, the estimated distribution 
of the groundwater flow velocity conforms to the flow velocity law of the Fanshantou landslide and can be used as the basis for calculating the hydrodynamic pressure of each soil strip.

Based on the improved Bishop method and the groundwater velocity information in Section 3.2, the safety factor of the Fanshantou landslide is calculated. Table 2 shows the safety factor of the Fanshantou landslide under three kinds of groundwater conditions. Without considering the effect of the groundwater, the safety factor of the Fanshantou landslide is 1.443 . This safety factor indicates that the slope is quite stable and basically no landslide hazards would occur. When only considering the hydrostatic pressure of the landslide groundwater, the safety factor of the landslide is 1.129. There is a decrease of 0.314 compared to when the effect of the groundwater was not considered and the decline is very obvious. However, neither safety factors seem to agree with the obvious damage characteristics of the case landslide. With such safety factors, so many landslide cracks should not occur. When considering the hydrodynamic pressure of the landslide, the safety factor is 1.009 , which is a decrease of 0.12 compared to when only the hydrostatic effect is considered. Combined with the landslide damage characteristics of the case, it is believed that this safety factor could reflect the true state of the landslide.

Table 2. Safety factor considering different groundwater conditions.

\begin{tabular}{cccc}
\hline Drainage Conditions & $\begin{array}{c}\text { No Consideration of } \\
\text { Groundwater }\end{array}$ & $\begin{array}{c}\text { Traditional Bishop } \\
\text { Method }\end{array}$ & $\begin{array}{c}\text { Improved Bishop } \\
\text { Method }\end{array}$ \\
\hline Before drainage & 1.443 & 1.129 & 1.009 \\
After drainage & 1.443 & 1.389 & 1.321 \\
\hline
\end{tabular}

The calculation result of the safety factor when considering the hydrodynamic pressure proves that for some landslides with strong groundwater activity, such as the case landslide, the stability of the slope cannot be accurately described without considering the groundwater effect or only considering the water pressure of the groundwater pore. For the case landslide, the safety factor calculated without considering the hydrodynamic pressure indicates that the landslide is pretty stable. However, when considering the hydrodynamic pressure, the calculation results show that the landslide is not stable and the results agree with the actual failure characteristics of the landslide. Therefore, the meticulous investigation of the hydrogeological conditions of landslides is very important. It is also necessary to evaluate the geological condition carefully because the geological and morphological settings of an area guide the physics of the soil. They will provide important data to evaluate the stability of the slope.

The calculation results show that groundwater is an important factor affecting the stability of the Fanshantou landslide. Therefore, the most effective way to control this type of landslide is to reduce the groundwater level of the landslide. After the groundwater level drops, the groundwater in an area changes in two ways. On the one hand, a drop in the groundwater level (measured by a pressure gauge) causes a decline in the hydraulic gradient of the landslide, which lowers the groundwater flow velocity at the trailing edge of the landslide. On the other hand, the drop in the groundwater level makes the confined water pressure of the leading edge drop or even disappear where the groundwater flow velocity is reduced. On these bases, the siphon drainage method was used to control the landslide. After siphon drainage of 100 days, the flow velocity of the slope was measured again (shown as Figure 11). Compared with the situation before treatment, the groundwater flow velocity at the leading edge and trailing edge of the slope decreased significantly. The safety factor of the landslide with the groundwater level and flow velocity after the treatment is recalculated. When only considering the pore water pressure, the safety factor of the landslide is 1.389 , and when considering the hydrodynamic pressure, the safety factor of the landslide is 1.321. This shows that after the groundwater level drops, the safety factor of the landslide is obviously improved. 


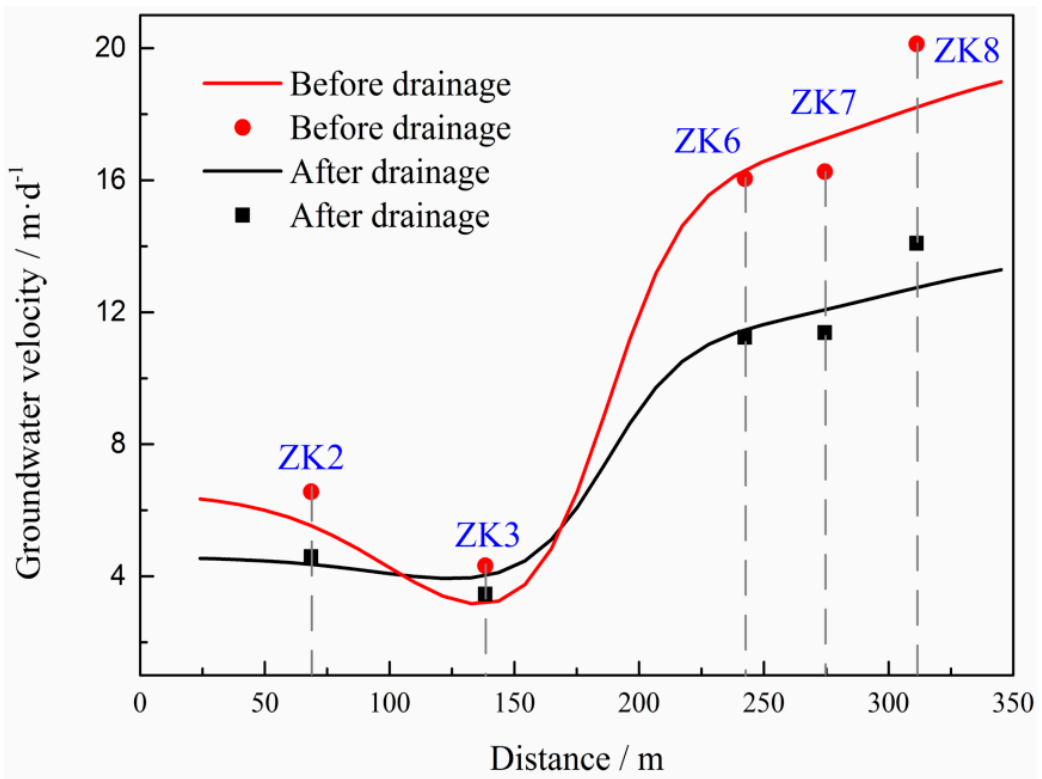

Figure 11. Groundwater flow velocity and fitting curves before and after drainage.

\section{Discussion}

The FVDS can measure the velocity of the groundwater in an area and obtain the hydrodynamic pressure of the groundwater on the soil. The application of the FVDS to slope stability analysis is innovative research. The monitoring of hydrodynamic pressure is indeed very important for the stability of some landslides, at least for the case studied in this article. However, whether hydrodynamic pressure will affect the stability of all slopes remains to be explored. On the one hand, it is related to the hydrogeological conditions of the landslide, and on the other hand, it is related to the monitoring conditions of the landslide. Therefore, this limits the wide application of the FVDS. However, indoor trials seem to solve this problem. Ivanov et al. [24] used indoor experiments to carefully explore the influence of groundwater on the stability analysis of shallow landslides and confirmed that indoor experiments can reflect all the problems of the original scale according to Buckingham's law. Therefore, indoor experiments using the FVDS can ensure more systematic applications of the system. The ANN method also played an important role in this analysis. The application of this method is based on the continuity of groundwater flow rate. Discussion on the accuracy and extensiveness of its fitting is still needed. However, the models and results used in this article are adequate when explaining trends and conducting preliminary analysis.

\section{Conclusions}

In this study, an improved Bishop method was proposed by incorporating hydrodynamic pressure and the artificial neural networks and the effectiveness of the framework was validated based on a case slope using the FVDS. The conclusions can be summarized as follows:

First, the FVDS provides a fast, convenient, and simple solution for measuring the direction and velocity of groundwater. The hydrodynamic information about groundwater in a landslide area can therefore be extracted, which is of great significance in analyzing the stability of the landslide. Meanwhile, the ANN exhibits optimal performance on fitting the curve of the groundwater flow velocity in a landslide. The results obtained from the ANN correspond with the actual hydrogeological conditions and measurement results and can be applied to subsequent analysis and calculation. The application of ANN can overcome the problem of limited data points caused by the strict requirements of the FVDS in the measurement procedure in the real-world application. 
Secondly, the original Bishop method has been improved by considering the hydrodynamic pressure. An updated approach is derived and proposed that can improve the calculation of the safety factor by adding a simple yet effective term of hydrodynamic pressure.

Finally, in the case landslide, the improved safety factor calculation formula was used to calculate the stability. As shown in the results section for the case landslide, the safety factors using the baseline methods without considering groundwater and incorporating only the pore water pressure were 1.443 and 1.129 , respectively. The safety factors by these two baseline methods did not match the failure characteristics of the case landslide. On the other hand, the safety factor considering the hydrodynamic pressure was 1.009, which conforms to the landslide failure characteristics. The feasibility and effectiveness of the proposed improved calculation method of safety factor in evaluating the stability of landslide is therefore shown. Moreover, we found that slope drainage is the most effective intervention strategy for the case of landslides. The result shows that the safety factor increased to 1.321 after the water level dropped.

Author Contributions: Conceptualization, Q.G. and Z.C.; methodology, Q.G.; software, Z.C.; validation, J.Z. and J.L.; formal analysis, J.Z.; investigation, Q.G.; resources, Z.C.; data curation, Z.C.; writing — original draft preparation, Z.C.; writing—review and editing, Q.G. All authors have read and agreed to the published version of the manuscript.

Funding: This research received no external funding.

Institutional Review Board Statement: Not applicable.

Informed Consent Statement: Not applicable.

Data Availability Statement: Due to the nature of this research, participants of this study did not agree for their data to be shared publicly, so supporting data is not available.

Acknowledgments: The authors acknowledge the support of the National Key R\&D Program of China (Project no. 2018YFC1504704).

Conflicts of Interest: The authors declare no conflict of interest.

\section{References}

1. Sun, H.-Y.; Wong, L.N.Y.; Shang, Y.-Q.; Shen, Y.-J.; Lu, Q. Evaluation of drainage tunnel effectiveness in landslide control. Landslides 2010, 7, 445-454. [CrossRef]

2. Corominas, J.; Moya, J.L.; Ledesma, A.; Lloret, A.; Gili, J.A. Prediction of ground displacement and velocities from groundwater level changes at the Vallcebre landslide (Eastern Pyrenees, Spain). Landslides 2005, 2, 83-96. [CrossRef]

3. Conte, E.; Troncone, A. A performance-based method for the design of drainage trenches used to stabilize slopes. Eng. Geol. 2018, 239, 158-166. [CrossRef]

4. Wei, Z.; Shang, Y.; Sun, H.; Xu, H.; Wang, D. The effectiveness of a drainage tunnel in increasing the rainfall threshold of a deep-seated landslide. Landslides 2019, 16, 1731-1744. [CrossRef]

5. Thakur, J.K. Hydrogeological modeling for improving groundwater monitoring network and strategies. Appl. Water Sci. 2016, 7, 3223-3240. [CrossRef]

6. Pimentel, E.T.; Hamza, V.M. Use of geothermal methods in outlining deep groundwater flow systems in Paleozoic interior basins of Brazil. Hydrogeol. J. 2013, 22, 107-128. [CrossRef]

7. Lv, H.; Ling, C.; Hu, B.X.; Ran, J.; Zheng, Y.; Xu, Q.; Tong, J. Characterizing groundwater flow in a translational rock landslide of southwestern China. Bull. Eng. Geol. Environ. 2019, 78, 1989-2007. [CrossRef]

8. Kearl, P.M. Observations of particle movement in a monitoring well using the colloidal borescope. J. Hydrol. 1997, 1, 344. [CrossRef]

9. Malkovsky, V.I.; Pek, A. Effect of Elevated Velocity of Particles in Groundwater Flow and Its Role in Colloid-facilitated Transport of Radionuclides in Underground Medium. Transp. Porous Media 2009, 78, 277-294. [CrossRef]

10. Osorno, T.; Devlin, J.F.; Firdous, R. An In-Well Point Velocity Probe for the rapid determination of groundwater velocity at the centimeter-scale. J. Hydrol. 2018, 557, 539-546. [CrossRef]

11. Kearl, P.M.; Roemer, K.; Rogoff, E.B.; Renn, A. Characterization of a fractured aquifer using the colloidal borescope. Adv. Environ. Res. 1999, 3, 67-73. 
12. Olea, S.; Escolero, O.; Mahlknecht, J.; Ortega, L.; Silva-Aguilera, R.; Florez-Penaloza, J.R.; Perez-Quezedas, J.; Zamora-Martinez, O. Identification of the components of a complex groundwater flow system subjected to intensive exploitation. J. S. Am. Earth Sci. 2020, 98, 24-34. [CrossRef]

13. Pan, P.; Shang, Y.Q.; Lü, Q.; Yu, Y. Periodic recurrence and scale-expansion mechanism of loess landslides caused by groundwater seepage and erosion. Bull. Eng. Geol. Environ. 2017, 78, 1143-1155. [CrossRef]

14. Deller, J.; Hansen, J.; Proakis, J. The Artificial Neural Network; Wiley-IEEE Press: Hoboken, NJ, USA, 2000.

15. Fung, A.; Bobcock, R., Jr. A Flow-Calibrated method to project groundwater infiltration into coastal sewers affected by sea level rise. Water 2020, 12, 1934. [CrossRef]

16. Chen, H.; Chiu, Y.; Tsai, T.; Yang, J. Effect of rainfall, runoff and infiltration processes on the stability of footslopes. Water 2020, 12, 1229. [CrossRef]

17. Lin, Q.; Wang, Y.; Liu, T.; Zhu, Y.; Sui, Q. The Vulnerability of People to Landslides: A Case Study on the Relationship between the Casualties and Volume of Landslides in China. Int. J. Environ. Res. Public Health 2017, 14, 212. [CrossRef]

18. Petrucci, O.; Salvati, P.; Aceto, L.; Bianchi, C.; Pasqua, A.; Rossi, M.; Guzzetti, F. The Vulnerability of People to Damaging Hydrogeological Events in the Calabria Region (Southern Italy). Int. J. Environ. Res. Public Health 2018, 15, 48. [CrossRef]

19. Roy, S.; Lee, J.; Baldi, S. A New Continuous-Time Stability Perspective of Time-Delay Control: Introducing a State-Dependent Upper Bound Structure. IEEE Control Syst. Lett. 2019, 3, 1. [CrossRef]

20. Roy, S.; Lee, J.; Baldi, S. A New Adaptive-Robust Design for Time Delay Control under State-Dependent Stability Condition. IEEE Trans. Control Syst. Technol. 2020, 99, 1-8. [CrossRef]

21. Liu, Z.; Li, H.; Cao, G. Quick Estimation Model for the Concentration of Indoor Airborne Culturable Bacteria: An Application of Machine Learning. Int. J. Environ. Res. Public Health 2017, 14, 857. [CrossRef]

22. Wan, H.; Bian, J.; Wu, J.; Sun, X.; Wang, Y.; Jia, Z. Prediction of Seasonal Frost Heave Behavior in Unsaturated Soil in Northeastern China Using Interactive Factor Analysis with Split-Plot Experiments and GRNN. Water 2019, 11, 1587. [CrossRef]

23. Dong, J.; Dai, W.; Xu, J.; Li, S. Spectral Estimation Model Construction of Heavy Metals in Mining Reclamation Areas. Int. J. Environ. Res. Public Health 2016, 13, 640. [CrossRef] [PubMed]

24. Ivanov, V.; Arosio, D.; Tresoldi, G.; Hojat, A.; Zanzi, L.; Papini, M.; Longono, L. Investigation on the role of water for the stability of shallow landslides-Insights from experimental tests. Water 2020, 12, 1203. [CrossRef] 